\title{
Laju Pertumbuhan Spesifik Larva Ikan Botia (Chromobotia macrachantus) Pada Pemeliharaan Dengan Suhu Yang Berbeda
}

\author{
${ }^{1}$ Husna Daya Aulia, ${ }^{2}$ Muhammad Sugihartono, dan ${ }^{2}$ Muarofah Ghofur \\ ${ }^{1}$ Alumni Program Studi Budidaya Perairan, Fakultas Pertanian Universitas Batanghari Jambi \\ ${ }^{2}$ Program Studi Budidaya Perairan Fakultas Pertanian Universitas Batanghari Jambi \\ J1. Slamet Riyadi, Broni Jambi. 36122. Telp. +62074160103 \\ 1e-mail : husnadayaaulya@gmail.com
}

\begin{abstract}
Temperature is one of the qualities parameter of water that is essential for fish life, especially growth rate. Temperature is very closely related to growth through the metabolism that continues to interact and is suspected to continue during maintenance, and the larval phase is the most critical time of the life of fish. In the maintenance effort, the resulting rate of growth of larvae becomes an important factor, as supporting production success until the next phase. Therefore, to know the specific level of growth (SGR) larvae of Botia fish (Chromobotia macrachantus) carried out research on optimal temperature with the treatment temperature of $24^{\circ} \mathrm{C}, 26^{\circ} \mathrm{C}, 28^{\circ} \mathrm{C}$ and $30^{\circ} \mathrm{C}$. The water quality parameters of $\mathrm{CO} 2, \mathrm{NH} 3, \mathrm{DO}$, and pH are carried out at the beginning and end of the research conducted over 28 days. The results showed that the specific growth rate (SGR) of botia larva was obtained at the treatment of B (temperature $26^{\circ} \mathrm{C}$ ) of $4.74 \%$. Water quality of research results include CO2 of $0.7338 \mathrm{mg} / \mathrm{L}$, $\mathrm{NH} 3$ of $0.0018 \mathrm{mg} / \mathrm{L}, \mathrm{DO}$ of $6.4 \mathrm{mg} / \mathrm{L}$ and $\mathrm{pH}$ of water at 6.68.
\end{abstract}

Keywords: Larva Botia, Specific Growth Rate, Temperature

\begin{abstract}
Abstrak. Suhu merupakan salah satu parameter kualitas air yang sangat penting bagi kehidupan ikan, terutama laju pertumbuhan. Suhu sangat erat kaitannya dengan pertumbuhan karena terkait dengan metabolisme yang terus berinteraksi dan akan terus terjadi selama pemeliharaan, dan fase larva merupakan masa yang paling kritis selama masa kehidupan ikan. Dalam upaya pemeliharaan, tingkat pertumbuhan larva yang dihasilkan menjadi faktor penting, sebagai penunjang keberhasilan produksi hingga mencapai fase selanjutnya. Oleh karena itu, untuk mengetahui tingkat pertumbuhan secara spesifik (SGR) larva ikan botia (Chromobotia macrachantus) dilakukan penelitian mengenai suhu optimal dengan suhu perlakuan $24^{\circ} \mathrm{C}, 26^{\circ} \mathrm{C}, 28^{\circ} \mathrm{C}$ dan $30^{\circ} \mathrm{C}$. Parameter kualitas air yaitu $\mathrm{CO}_{2}, \mathrm{NH}_{3}$, DO, dan $\mathrm{pH}$ dilakukan pada awal dan akhir penelitian yang dilakukan selama 28 hari. Hasil penelitian perlakuan B (suhu $26^{\circ} \mathrm{C}$ ) sebesar $4.74 \%$. Kualiltas air hasil penelitian meliputi $\mathrm{CO}_{2}$ sebesar $0.7338 \mathrm{mg} / \mathrm{L}, \mathrm{NH}_{3} \mathrm{sebesar} 0.0018$ $\mathrm{mg} / \mathrm{L}$, DO sebesar $6.4 \mathrm{mg} / \mathrm{L}$ dan $\mathrm{pH}$ air sebesar 6.68 .
\end{abstract}

Kata Kunci : Laju Pertumbuhan Spesifik, Larva Botia, Suhu

\section{PENDAHULUAN}

Ikan mempunyai toleransi tertentu terhadap kisaran suhu yang berfluktuatif. Suhu mempunyai peran penting dalam budidaya terutama pertumbuhan, konversi pakan, kelangsungan hidup dan resistensi terhadap penyakit, ikan akan mudah mengalami stress apabila terjadi perubahan suhu. Pada dasarnya suhu rendah memungkinkan air mengandung oksigen kebih tinggi, tetapi suhu rendah menyebabkan stres pernafasan pada larva berupa penurunan laju respirasi dan denyut jantung sehingga dapat berlanjut dengan pingsannya larva akibat kekurangan oksigen. Suhu air yang relatif tinggi dapat ditandai dengan munculnya ikan-ikan dan hewan air lainnya ke permukaan untuk mencari oksigen. Sebagai gambaran suhu terbaik untuk pertumbuhan dan kelangsungan hidup ikan botia adalah $27^{\circ} \mathrm{C}$ (Panjaitan, 2004).

Suhu merupakan salah satu kualitas air yang sangat penting bagi kehidupan ikan, menentukan pertumbuhan, tingkat kelangsungan hidup, dan perubahan morfologis. Untuk itu keberhasilan pemeliharaan sangat bergantung pada suhu yang optimal. Korelasi antara suhu dengan laju pertumbuhan sangat erat yaitu melalui proses metabolisme yang terus berinteraksi dan akan terus terjadi selama pemeliharaan terutama fase larva. Fase larva merupakan masa yang paling kritis selama masa kehidupan ikan, sehingga penulis tertarik untuk melakukan penelitian "Laju Pertumbuhan Spesifik Larva Ikan Botia (Chromobotia macrachantus) pada pemeliharaan Dengan Suhu Yang Berbeda" agar dapat ketahui secara akurat hubungan antar faktor sehingga didapatkan suhu yang optimal terhadap laju pertumbuhan. Tujuan penelitian ini adalah untuk mengetahui kisaran suhu optimal bagi larva ikan botia sehingga dapat menunjang laju pertumbuhan.

\section{METODOLOGI PENELITIAN}

Penelitian ini dilaksanakan selama 1 bulan terhitung dari bulan Desember 2017-Januari 2018 bertempat di Balai Benih Ikan Daerah Telanaipura, Provinsi Jambi. Bahan yang digunakan selama pelaksanaan penelitian ini adalah larva ikan botia sebanyak 1.008 ekor yang berasal dari hasil kerjasama antara Balai Penelitian dan Pengembangan Budidaya Ikan Hias (BPPBIH) Depok, Jawa Barat. Sementara ikan ditimbang bobotnya menggunakan timbangan digital dengan ketelitian $0.01 \mathrm{~g}$ dan diukur panjangnya menggunakan mistar dan millimeter blok dengan panjang 30 $\mathrm{cm}$. Larva ikan botia dipelihara di dalam akuarium berukuran $60 \times 30 \times 40 \mathrm{~cm}$, pengambilan larva botia pada saat 
Husna Daya Aulia, Muhammad Sugihartono, dan Muarofah Ghofur. Laju Pertumbuhan Spesifik Larva Ikan Botia (Chromobotia macrachantus) Pada Pemeliharaan Dengan Suhu Yang Berbeda

sampling menggunakan serok halus dan dimasukkan ke dalam mangkok, kemudian untuk pengukuran panjang larva botia diambil menggunakan sendok. Kualitas air harus selalu dijaga dengan cara dilakukan penyifonan menggunakan selang sifon setiap hari. Hasil dari pengukuran pada saat sampling dicatat dan kegiatan sampling didokumentasikan menggunakan kamera dan kualitas air diukur menggunakan water test kit. Rancangan penelitian yang dilakukan menggunakan model Rancangan Acak Lengkap (RAL) yang terdiri dari 4 perlakuan dan 3 kali ulangan, masingmasing perlakuan tersebut adalah $24^{\circ} \mathrm{C}, 26^{\circ} \mathrm{C}, 28^{\circ} \mathrm{C}$ dan $30^{\circ} \mathrm{C}$.

Air yang digunakan dalam penelitian telah diendapkan selama kurang lebih 3 hari sehingga dapat digunakan sebagai media hidup larva. Tujuan pengendapan air adalah untuk meminimalisir adanya senyawa yang tidak baik bagi pemeliharaan. Wadah pemeliharaan yang digunakan adalah akuarium dengan ukuran 60x30x40 cm sebanyak 12 buah dicuci bersih dan dikeringkan, tujuannya untu membersihkan sisa-sisa kotoran yang dikhawatirkan akan membawa penyakit, kemudian akuarium disusun sesuai dengan denah penelitian.

Dapat diketahui volume air yaitu 24 liter dengan tinggi air yang ditentukan $10 \mathrm{~cm}$, kemudian diberikan aerasi dengan tekanan kecil agar menunjang ketersediaan oksigen terlarut bagi larva. Setelah akuarium terisi air, maka dilakukanlah setting water thermostat sesuai perlakuan suhu yang telah dirancang dan dibiarkan selama 1 x 24 jam agar penetrasi suhu merata untuk kemudian dapat dimasukkan larva ikan pada perlakuan.

Sebelum dimasukkan kedalam wadah perlakuan larva ikan sebelumnya telah diaklimatisasi atau penyesuaian suhu larva yang berasal dari BPPBIH Depok, Jawa Barat pada bak fiber selama 1 minggu guna mencegah tingkat mortalitas tinggi yang dapat menyebabkan larva mengalami stres akibat perubahan lingkungan yang drastis.

Setelah seluruh wadah pemeliharaan siap digunakan, selanjutnya secara perlahan dan berhati-hati yaitu dengan tidak secara langsung memasukkan larva ke masing-masing perlakuan, wadah yang digunakan untuk memasukkan larva ikan botia dimiringkan agar kondisi larva yang telah diaklimatisasi berumur 10 hari (larva fase kritis) tidak mengalami perubahan drastis terhadap suhu media perlakuan. Panjang rata-rata $0,6 \mathrm{~cm}$ dengan padat tebar masingmasing 3 ekor/l sesuai dengan rancangan penelitian yang dilakukan yakni : Akuarium A suhu $24{ }^{\circ} \mathrm{C}$, Akuarium B $26^{0}$ C, $28^{\circ}$, D $30^{\circ}$ C. Jadi jumlah larva ikan pada setiap wadah berjumlah 84 ekor, dengan total keseluruhan 1.008 ekor. Larva yang dipelihara dengan perlakuan tersebut diberi pakan artemia denngan metode adlibitum (selalu tersedia) yang ditetaskan terlebih dahulu dengan cara merendam cyst selama \pm 24 jam, kemudian dipanen dengan memisahkan naupli yang menetas dan disaring menggunakan kain halus lalu dibilas menggunakan air tawar dan diberikan hingga 15 hari pertama larva lalu dilanjutkan dengan pemberian cacing sutera pada setiap akuarium perlakuan hingga hari ke 28 penelitian dengan metode pemberian makan secara kenyang/satiasi sebanyak 6 kali sehari. Sampling pengukuran dan penimbangan dilakukan setiap minggu, demikian halnya dengan kualitas air yakni suhu tetap dilakukan setiap hari dan keseluruhannya pada akhir penelitian. Parameter yang diamati selama penelitian adalah :

\section{Laju Pertumbuhan Spesifik}

Laju pertumbuhan spesifik (specific growth rate, SGR) adalah laju pertumbuhan bobot harian ikan, yang dihitung dengan rumus Steffens (1989):

$S G R=\frac{\ln W t-\ln W o}{T} \times 100 \%$

Keterangan : SGR $=$ Laju pertumbuhan spesifik $(\%)$

$\mathrm{t} \quad=$ Waktu pemeliharaan (hari)

$\mathrm{Wt}=$ Bobot rata-rata ikan pada akhir pemeliharaan (gram/ekor)

$\mathrm{Wo}=$ Bobot rata-rata ikan pada awal pemeliharaan (gram/ekor)

\section{Kualitas Air}

Parameter kualitas air yang akan diamati yakni : $\mathrm{Suhu}, \mathrm{O}_{2}, \mathrm{CO}_{2}$, $\mathrm{pH}$ dan $\mathrm{NH}_{3}$. Pengukuran suhu dilakukan setiap hari menggunakan thermometer dan water test kit. Penggantian air pada masing-masing wadah akuarium percobaan dilakukan setiap kali sampling sebanyak 50\% volume air. Penyiponan dilakukan 2 hari sekali.

Untuk melihat pengaruh suhu yang berbeda terhadap pertumbuhan dan kelangsungan hidup ikan botia $(C$. macrachantus) akan dianalisis dengan menggunakan sidik ragam (ANOVA) dan dengan uji lanjut BNJ pada taraf $5 \%$ SPSS 20, serta data lain yang akan menunjang analisa penelitian akan dilakukan secara deskriptif. 
Husna Daya Aulia, Muhammad Sugihartono, dan Muarofah Ghofur. Laju Pertumbuhan Spesifik Larva Ikan Botia (Chromobotia macrachantus) Pada Pemeliharaan Dengan Suhu Yang Berbeda

\section{HASIL DAN PEMBAHASAN}

Hasil persentase laju pertumbuhan spesifik masing-masing perlakuan yang divisualisasikan pada gambar 3 terlihat nilai laju pertumbuhan spesifik untuk perlakuan A, B, C, dan D adalah 3,84\%, 4,74\%, 4,63\%, 4,50\%. Berdasarkan analisa statistik anova menunjukkan bahwa perlakuan dengan perbedaan suhu media $24^{\circ} \mathrm{C}, 26^{\circ} \mathrm{C}, 28^{\circ} \mathrm{C}$, $30^{\circ} \mathrm{C}$, tidak memberikan pengaruh $(\mathrm{P}>0,05)$ terhadap laju pertumbuhan spesifik larva ikan botia (C.macrachantus) meski nilai perlakuan $\mathrm{B}$ dan $\mathrm{C}$ mengalami peningkatan dengan semakin meningkatnya suhu perlakuan. Namun hasil penelitian menunjukkan bahwa perlakuan B suhu $26^{\circ} \mathrm{C}$ yaitu sebesar $4.74 \%$ menghasilkan laju pertumbuhan spesifik tertinggi, diikuti perlakuan $\mathrm{C}$ suhu $26^{\circ} \mathrm{C}$ sebesar $4.63 \%$, lalu menurun pada perlakuan $\mathrm{D}$ suhu $30^{\circ} \mathrm{C}$ sebesar $4.5 \%$ dan persentase terendah pada perlakuan A kisaran suhu $24^{\circ} \mathrm{C}$ yaitu $3.84 \%$.

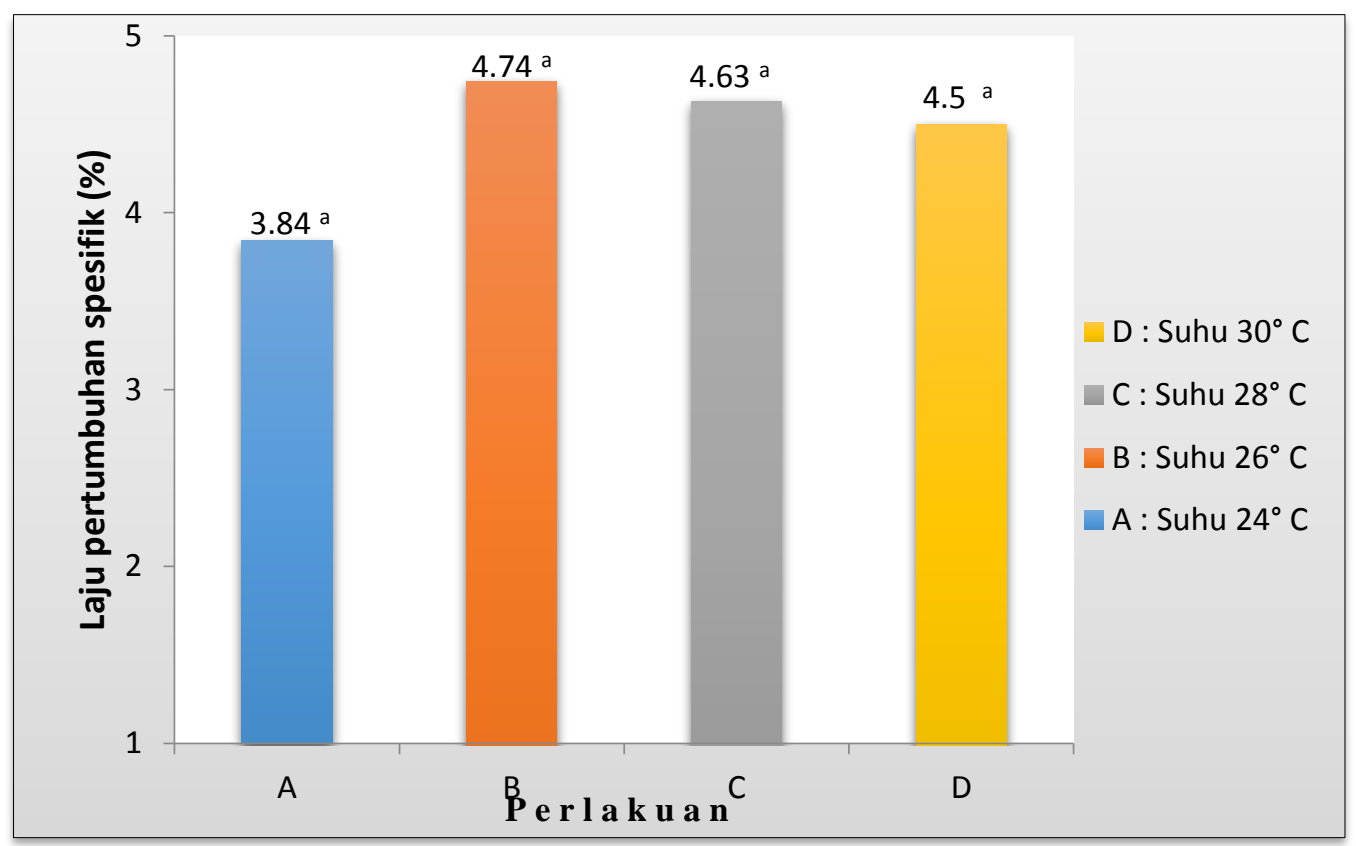

Gambar 1. Laju Pertumbuhan Spesifik (\%) pada berbagai suhu media $\left({ }^{\circ} \mathrm{C}\right)$

Kejadian pada gambar 1 di atas dapat terjadi karena beda suhu air pada media pemeliharaan dengan suhu tubuh ikan yang berpengaruh terhadap proses metabolisme tubuh ikan. Akibatnya sebagian besar energi yang tersimpan dalam tubuh ikan digunakan untuk menyesuaikan diri terhadap lingkungan yang kurang optimal tersebut. Kondisi pada gambar 1 menunjukkan bahwa perlakuan B suhu $28^{\circ} \mathrm{C}$ memberikan laju pertumbuhan spesifik yang lebih baik dibandingkan perlakuan A. Hal ini membuktikan bahwa suhu optimal untuk pertumbuhan adalah pada perlakuan B.

\section{Kualitas Air}

Laju pertumbuhan ikan selain dipengaruhi oleh suhu dipengaruhi juga oleh faktor yang lain misalnya oksigen terlarut, karbondioksida, $\mathrm{pH}$ yang berfluktuasi dan kandungan ammonia $\left(\mathrm{NH}_{3}\right)$ yang terakumulasi dari sisa pakan dan limbah metabolisme ikan (feses dan urine). Untuk mengatasi hal tersebut, harus dilakukan dengan cara mengelola kualitas air dengan baik seperti pengontrolan secara intensif, penyiponan untuk membuang sisa pakan dan kotoran, serta pergantian air. Pengukuran dilakukan pada awal dan akhir penelitian yang dianalisis pada laboratorium dasar Universitas Batanghari Jambi. Hasil pengukuran parameter kualitas air selama penelitian dapat dilihat pada Tabel 5 dibawah ini.

Tabel 1. Hasil Pengukuran Parameter Kualitas Air Selama Penelitian

\begin{tabular}{cccccc}
\hline \multirow{2}{*}{ Parameter Kualitas Air } & \multicolumn{4}{c}{ Perlakuan } & \multirow{2}{*}{ Baku Mutu } \\
\cline { 2 - 5 } & $\mathrm{A}$ & $\mathrm{B}$ & $\mathrm{C}$ & $\mathrm{D}$ & \\
\hline Suhu $\left({ }^{0} \mathrm{C}\right)$ & 24 & 26 & 28 & 30 & $24-30^{0} \mathrm{C}$ (Satyani et al) \\
$\mathrm{CO}_{2}$ & 0.7179 & 0.7338 & 0.7498 & 0.7657 & $0.7-0.85 \mathrm{mg} / \mathrm{l}$ (Lab. Dasar UNBARI) \\
Amonia $\left(\mathrm{NH}_{3}\right)$ & 0.0017 & 0.0018 & 0.0018 & 0.0019 & $0.2 \mathrm{mg} / \mathrm{l}$ (Lab. Dasar UNBARI) \\
$\mathrm{DO}$ & 6.5 & 6.4 & 7.5 & 7.2 & $<10 \mathrm{mg} / \mathrm{l}$ (Zonneveld, et al 1991) \\
$\mathrm{pH}$ & 7.89 & 6.68 & 7.06 & 6.73 & $7-8.5$ (Barus, 2001) \\
\hline
\end{tabular}


Husna Daya Aulia, Muhammad Sugihartono, dan Muarofah Ghofur. Laju Pertumbuhan Spesifik Larva Ikan Botia (Chromobotia macrachantus) Pada Pemeliharaan Dengan Suhu Yang Berbeda

Dari hasil pengukuran kualitas air yang tertera pada tabel 2 dapat dilihat kualitas air selama masa penelitian pada setiap perlakuan. Secara umum dan berdasarkan baku mutu yang ditetapkan hasilnya menunjukkan bahwa kisaran masing-masing parameter tersebut masih berada pada derajat tolerasi yang dapat diterima bagi larva ikan botia yang diberi perlakuan suhu berbeda.

Kisaran kualitas air yang optimum akan sangat mendukung kehidupan ikan, tetapi apabila kualitas air berada di luar kisaran optimum akan menyebabkan stress pada ikan, sehingga dikhawatirkan ikan akan mudah terserang penyakit, sehingga sangat penting untuk memperhatikan kondisi kualitas air agar tetap berada pada kisaran normal.

Salah satu faktor keberhasilan dalam budidaya ditentukan oleh suhu. Terkait dengan hal ini, ikan merupakan hewan berdarah dingin, yaitu hewan yang suhu tubuhnya dipengaruhi oleh suhu lingkungan. Suhu tinggi akan menyebabkan kenaikan proses metabolisme tubuh ikan sehingga akan menyebabkan terjadinya peningkatan intensitas pembuangan kotoran dan akan menyebabkan menurunnya kandungan oksigen terlarut dalam perairan (Kartamiharja, 2008).

Suhu media pemeliharaan larva ikan botia selama penelitian berkisar $24^{\circ} \mathrm{C}-30^{\circ} \mathrm{C}$, sesuai dengan perlakuan yang diujikan. Kisaran ini juga merupakan kisaran yang ideal untuk ikan botia. Secara langsung, suhu sangat berpengaruh besar terhadap segala aktifitas yang berlangsung bagi kehidupan ikan, yang dapat berpengaruh pula terhadap parameter kualitas air lainnya. Dan dapat diketahui pula, semakin tinggi suhu media pemeliharaan maka nilai kelangsungan hidup, laju pertumbuhan spesifik dan tingkat kelangsungan hidup larva ikan botia mengalami penurunan. Dan suhu terbaik yang paling menunjukkan hasil positif pada parameter uji adalah perlakuan B suhu $26^{\circ} \mathrm{C}$.

Nilai karbondioksida $\left(\mathrm{CO}_{2}\right)$ berkisar antara $0.7179-0.7657 \mathrm{mg} / \mathrm{l}$ dan nilai ini merupakan kisaran yang tergolong normal bagi keberlangsungan hidup larva ikan botia. Karbondioksida merupakan hasil buangan akibat adanya proses pernafasan makhluk hidup (Effendi, 2003). Pada konsentrasi tinggi (> $10 \mathrm{mg} / \mathrm{l}$ ), karbondioksida dapat beracun karena keberadaannya didalam darah dapat menekan aktifitas pernapasan ikan dan menghambat pengikatan oksigen oleh hemoglobin sehingga dapat membuat ikan menjadi stress. Kandungan karbondiokisa didalam air untuk pembesaran ikan sebaiknya kurang dari $10 \mathrm{mg} / \mathrm{l}$ (Zonneveld et al. 1991)

Amonia dihasilkan dari proses perombakan pakan yang dikonsumsi oleh ikan guna proses pertumbuhan kelangsungan hidup. Dan sisa perombakan dibuang berupa kotoran (faeces). Pada penelitian ini, konsentrasi ammonia pada perlakuan $\mathrm{D}$ suhu $30^{\circ} \mathrm{C}$ adalah yang tertinggi senilai $0.0019 \mathrm{mg} / \mathrm{l}$ dibandingkan perlakuan dengan nilai terendah A $24^{0}$ yaitu $0.0017 \mathrm{mg} / \mathrm{l}, \mathrm{B} 26^{\circ} \mathrm{C}$ dan C $28^{\circ} \mathrm{C}$ sebesar $0.0018 \mathrm{mg} / \mathrm{l}$. Akan tetapi nilai pada ke- 4 perlakuan masih dalam toleransi pemeliharaan larva ikan botia dan kondisi tersebut tidak membahayakan bagi larva ikan botia. Tingkat toksisitas dari ammonia juga dapat dipengaruhi oleh berbagai macam hal lainnya saling terkait antar parameter kualitas air. Dan konsentrasi yang melewati kisaran baku mutu $0.2 \mathrm{mg} / \mathrm{l}$ dapat mengakibatkan terjadinya perlambatan laju pertumbuhan dan menyebabkan kematian akut.

Oksigen terlarut merupakan oksigen yang terlarut dalam air hasil dari proses difusi oksigen dari udara. Ikan hanya dapat memanfaatkan oksigen dalam bentuk terlarut dalam air, tidak dapat mengambil langsung dari udara. Secara umum, ikan-ikan kecil memanfaatkan oksigen lebih banyak dibandingkan dengan ikan yang lebih besar dalam satu spesies (Samsundari dan Ganjar, 2013 dalam Emaliana et al. 2016). Hasil pengukuran kandungan oksigen pada penelitian ini dikategorikan optimum dan mendukung kehidupan ikan yaitu $<10 \mathrm{mg} / \mathrm{L}$, berkisar antara $5.9 \mathrm{mg} / \mathrm{L}$ hingga $7.5 \mathrm{mg} / \mathrm{L}$.

Derajat keasaman $(\mathrm{pH})$ air mengekspresikan intensitas asam maupun basa perairan, bentuk persamaan $\mathrm{pH}$ adalah logaritma negatif dari aktivitas ion hidrogen. Nilai $\mathrm{pH}$ bergantung pada parameter fisika kimia air lain seperti, kekeruhan, $\mathrm{CO}_{2}$, dan salinitas serta unsur biologis seperti perombakan bahan organik dan tingkat kepadatan ikan. $\mathrm{pH}$ sangat berfluktuatif didalam media pemeliharaan, dan pada umumnya kisaran normal yang dapat menunjang kegiatan pemeliharaan ikan botia adalah 5-7. Nilai $\mathrm{pH}$ sangat berpengaruh terhadap keberlangsungan aktifitas pemeliharaan dan berdasarkan hasil yang didapatkan, tentunya nilai tersebut cukup ideal dengan kisaran 6.68-7.89.

\section{KESIMPULAN}

Suhu media pemeliharaan tidak berpengaruh nyata terhadap laju pertumbuhan. Akan tetapi suhu yang paling optimal dengan menunjukkan hasil terbaik adalah suhu perlakuan B $26^{\circ} \mathrm{C}$ dengan laju pertumbuhan spesifik tertinggi sebesar $4.74 \%$ dan tingkat kelangsungan hidup sebesar $100 \%$. Hasil pengukuran kualitas air masing-masing parameter optimal dan mendukung kehidupan ikan yang dipelihara. 
Husna Daya Aulia, Muhammad Sugihartono, dan Muarofah Ghofur. Laju Pertumbuhan Spesifik Larva Ikan Botia (Chromobotia macrachantus) Pada Pemeliharaan Dengan Suhu Yang Berbeda

\section{DAFTAR PUSTAKA}

Aras A.K., Nirmala K., Soelistyowati D.T., Sudarto. 2015. Manipulasi Spektrum Cahaya terhadap Pertumbuhan dan Kualitas Warna Yuwana Ikan Botia (Chromobotia macracanthus, Blekeer 1852). Jurnal Iktiologi Indonesia, Vol. 16 No.1. 45-55.

Barus, A.T. 2001. Pengantar Limnologi. Direktoral Pembinaan Penelitian dan Pengabdian Pada Masyarakat. Direktorat Jenderal Pendidikan Tinggi. Jakarta. 81-93. 2004. Pengantar Limnologi. USU Press. Medan.

Baras E., Slembrouck J., Priyadi A., Satyani D., Pouyaud L., Legendre M. 2012. Biology and Culture of the Clown Loach Chromobotia macrachantus (Cypriniformes, Cobitidae): 3 Ontogeny, Ecological, and Aquacultural Implications. Aquat Living Resour. 25, 199-130.

Boyd, C. 1990. Water Quality in Ponds for Aquaculture. Alabama Agricultural Experiment Station, Aubum University, Birmingham Publishing Co. Birmingham, Alabama. Research and Development Series No. 22.

Darsono. 1992. Pengantar Ilmu Lingkungan. Universitas Atmajaya, Yogyakarta, hal : 66-68.

Effendie, M.I. 2002. Biologi Perikanan. Yayasan Pustaka Nusatama. Yogyakarta. 163 hal.

Effendi, H. 2000. Telaahan Kualitas Air Bagi Pengelolaan Sumberdaya dan Lingkungan Perairan. Fakultas Perikanan dan Ilmu Kelautan IPB, Bogor. 259 hal.

2003. Telaah Kualitas Air. Kanisius. Bogor. 246 hal.

Effendi, I. 2004. Pengantar Akuakultur. Penebar Swadaya. Jakarta.

Emaliana., Usman S., Lesmana I. 2016. Pengaruh Perbedaan Suhu Terhadap Pertumbuhan Benih Ikan Mas Koi (Cyprinus carpio). Program Studi Manajemen Sumberdaya Perairan, Fakultas Pertanian, Universitas Sumatera Utara, Medan.

Eni K dan Rahmawati R. 2016. Optimasi Suhu Pemeliharaan terhadap Pertumbuhan Larva Ikan Cupang (Betta imbellis). Prosiding Forum Inovasi Teknologi Akuakultur. Balai Penelitian dan Pengembangan Budidaya Ikan Hias. Depok, Jawa Barat.

Farida., Rachimi., Adrianus. 2016. Pengaruh Suhu yang Berbeda terhadap Waktu Penetasan dan Kelangsungan Hidup Larva Ikan Biawan (Helostoma temmincki). Jurnal Ruaya Vol. 4. No. 2 FPIK UNMUH-PNK. ISSN 254-3155.

Huisman, E.A. 1987. The principles of fish culture production. Department of Fish and Fisheries. Wageningen Agricultural University. Netherland. $170 \mathrm{p}$.

Hernawati. 2015. Inventarisasi Patogen pada Ikan Botia (Chromobotia macracanthus Bleeker) di Stasiun Karantina Ikan Kelas I Supadio, Pontianak. Jurnal Sain Veteriner. ISSN : 0126-0421.

Kamal, M. 1992. Bioekologi Ikan Botia (Chromobotia macracanthus) di Sungai Batanghari, Provinsi Jambi. [Skripsi]. Departemen Manajemen Sumberdaya Perairan. Fakultas Perikanan dan Ilmu Kelautan. Institut Pertanian Bogor. Bogor. 1-10.

Kartamihardja, E.S. 2008. Belajar dari keberhasilan introduksi ikan bilih di Danau Toba Sumatera Utara. Pusat Riset Perikanan Tangkap. Badan Riset Kelautan dan Perikanan.

Kelabora, D.M. 2010. Pengaruh Suhu terhadap Kelangsungan Hidup dan Pertumbuhan Larva Ikan Mas (Cyprinus carpio). Berkala Perikanan Terubuk. Vol 38 No. 1 hlm 71-81.

Kottelat, M. 2004. Botia kubotai, A new species of Loach (Teleostei:Cobitidae) From The Ataran River Basin (Myanmar), With Comments on Botine Nomenclature and Diagnosis of A new Genus. Zootaxa 401. 1. 1-18. Ref. 50472.

Kusumah, R.V. 2007. Struktur Populasi dan Sejarah Kolonisasi Ikan Botia (Chromobotia macracanthus BLKR) Berdasarkan Sequence (Urutan Basa) Intron dari Gen Aldolase B. [Skripsi]. Departemen Manajemen Sumberdaya Perairan. Fakultas Perikanan dan Ilmu Kelautan. Institut Pertanian Bogor. 69 hal.

Nurdawati., Samuel S., Prasetyo D. 2006. Sudah Anda Tahu? Ikan Botia (Botia macracanthus). Dalam : Berita Riset Kelautan dan Perikanan. DKP. http://www.dkp.go.id. [Diakses : 10 Januari 2018]

Nurhayati., Fauziyah., Bernas S.M. 2016. Hubungan Panjang-Berat dan Pola Pertumbuhan Ikan di Muara Sungai Musi Kabupaten Banyuasin, Sumatera Selatan. Maspari Journal. Vol. 8 No.2 : 111-118. ISSN : 2087-0558.

Panjaitan, E.F. 2004. Pengaruh Suhu Air yang Berbeda Terhadap Laju Pertumbuhan dan Kelangsungan Hidup Benih Ikan Botia (Botia macracanthus Bleeker). [Skripsi]. Program Studi Teknologi dan Manajemen Akuakultur. Fakultas Perikanan dan Ilmu Kelautan. Institut Pertanian Bogor. Bogor.

Permana A., Kusumah R.V., Priyadi A. 2011. Budidaya ikan botia (Chromobotia macracanthus Bleeker) sebagai model konservasi ex-situ. Prosiding Forum Nasional Pemacuan Sumber Daya Ikan III. Hasil Penelitian Perikanan dan Kelautan. Bandung

Putra H.F.E., Raharjo S.S.P., Permana A. 2017. Pemijahan Ikan Hias Botia (Chromobotia macracanthus Bleeker) secara Buatan dengan Injeksi Hormon HCG (Human Chorionic Gonadothropin) dan LHRH-A (Luteinizing Hormone Releasing Hormone Analog). Jurnal of Aquaculture and Fish Health. Vol 6 No.3. 
Husna Daya Aulia, Muhammad Sugihartono, dan Muarofah Ghofur. Laju Pertumbuhan Spesifik Larva Ikan Botia (Chromobotia macrachantus) Pada Pemeliharaan Dengan Suhu Yang Berbeda

Sari., M., Hatta M., Permana A. 2014. Pengaruh Ketinggian Air dalam Pemeliharaan Larva Ikan Hias Botia (Chromobotia macracanthus, Bleeker). Acta Aquatica. 24-30. ISSN. 2406-9825.

Satyani., Slembrouck J., Subandiyah S., Legendre M. 2006. Teknologi Pembenihan Ikan Hias Botia (Chromobotia macracanthus) Skala Laboratorium. IRD dan Departemen Kelautan dan Perikanan. Jakarta. ISSN : 9791522405.

2007. Pembenihan Ikan Hias Botia (Chromobotia macracanthus) Populasi Kalimantan. Loka Riset Budidaya Ikan Hias Air Tawar Depok, BRKP dan IRD. Vol. 2 No. 2. ISSN : 9791522405.

Slembrouck J., Priyadi A., Permana A., Ginanjar R., Baras E., Satyani D., Sudarto., Pouyaud L., Legendre M. 2012. Biology and Culture of the Clown loach Chromobotia macrachantus (Cypriniformes, cobitidae): 2Importance of Water Movement and Temperature during Egg Incubation. Aquat Living Resour. EDP Sciences. 25, 95-108.

Steffens, W. 1989. Principles of fish nutrition. Ellis Horwood Limited. West Sussex. England. 384 pp.

Sudarto dan Pouyaud, L. 2006. Perbedaan morfologi populasi Botia macracantha asal Sumatra dan Kalimantan. Jurnal Iktiologi Indonesia. Vol. 6 No. 2. 121- 124.

Sugihartono dan David. 2014. Respon Kelangsungan Hidup dan Pertumbuhan Larva terhadap Padat Tebar Ikan Tambakan (Hellostoma temmincki. C.V). Jurnal Ilmiah Universitas Batanghari Jambi. Vol. 14. No. 4. 103-107.

Sugihartono., Syarifuddin H., Mukhlis., Mutawali A., Rahman A., Lestari W Suarman., Nurjanah R.A. 2014. Khazanah Sumber Daya Genetik Ikan dan Ternak Provinsi Jambi. Badan Penelitian dan Pengembangan Daerah, Jambi. ISBN : 978-979-3861-51-7.

Soetjipta, 1993. Dasar-dasar Ekologi Hewan. Proyek Pembinaan Tenaga Kependidikan Pendidikan Tinggi. Dirjen Dikti Depdikbud. PPTLPT Jakarta.

Steel, R.G. D dan Terry 1991. Prinsip dan Prosedur Statistik. PT. Gramedia Pustaka Utama, Jakarta.

Sterba, G. 1969. Freshwater Fishes of The world. The Pet Library Ltd., New York. 877p. Vol. 10. Issues 8.

Suseno D dan Subandiah. 2000. Ciri Morfologis Jenis Ikan Macan Atau Botia Strain Batanghari, Musi, dan Kapuas. Prosiding Seminar Nasional Keanekaragaman Hayati Ikan.

Tarigan R.P., Yunasfi., Lesmana I. 2014. Laju Pertumbuhan dan Kelangsungan Hidup Benih Ikan Botia (Chromobotia macracanthus) dengan Pakan Cacing Sutera (Tubifex sp.). Jurnal Program Studi Manajemen Sumberdaya Perairan. USU. Vol 3 No 2.

Zonneveld. N, E. A. Huisman, J. H. Boon. 1991. Prinsip-Prinsip Budidaya Ikan. Gramedia Pustaka Umum. Jakarta. 